\section{For fast, effective disinfection in the practice}

For upgraded infection control OPTIM 1 wipes are available from COLTENE.
Part of the OPTIM 1 range, market-leading in the US, these wipes
will protect your team and your patients against a range of harmful
pathogens, including COVID-19.
To achieve disinfection, surfaces must remain wet for the entire
contact time - with OPTIM 1, the contact time is an astonishing one
minute!
Use them to wipe down areas quickly and safely - they have been
tested and passed for all common dental chairs.
Clean and disinfect in a single step - to learn more about
OPTIM 1, go to: https://www.scican.com/blog/2020/02/
is-optim-effective-against-novel-coronavirus/.
For more on COLTENE, visit www.coltene.com, email info.uk@
coltene.com or call 08002545115.

\section{What's in the box?}

Azento from Dentsply Sirona marks a new, convenient start-to-finish digital solution for planning, placing and restoring single tooth implants, custom-designed for every patient.

Azento reduces the need for a costly implant instrument and materials inventory, delivering everything you need for a single tooth case in one neatly packaged box. This not only looks great when presented to your patients, but also helps to reduce the number of visits and chairtime required for implant treatment.

Each patient receives a precise customised treatment plan recommendation based on their $\mathrm{CBCT}$ and intraoral scans, which are uploaded by the clinician to the Azento case management portal. Azento's clinical experts then plan the case and return for review and approval. Once approved, Azento takes care of manufacture, packing and delivery of all the required surgical and restorative components in a single, patient specific box.
Each Azento case includes:

- Surgical guide

- All necessary instruments

- A case-specific Astra Tech EV implant

- Atlantis healing abutment

- Atlantis temporary abutment and crown (optional).

Azento is redefining the approach to implant materials and workflows and is set to revolutionise the way in which clinicians plan and carry out implant treatment.

To learn more, listen to leading implant clinician Marcus Dagnelid as he discusses implant workflows with Azento in a 'Let's Talk Digital' webinar: https://www. dentsplysirona.com/en-gb/education/digitaltransformation-online-recordings.html.

To find out more and have a 1-to-1 consultation about how Azento could supplement your implant treatments, visit https://www.dentsplysirona.com/ en-gb/explore/implantology/azentodental-implant-procedure.html or call 01932838343 .

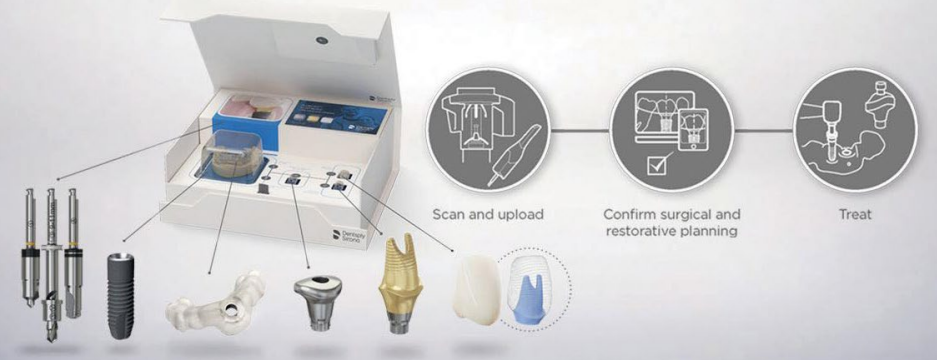

